\title{
Studies of the Cyclopolymerization in the Presence of Alkylaluminum Chlorides. V. Polymerization of o-Allylphenyl Methacrylate
}

\author{
Kazuaki YoKotA, Noriaki KANEKo, Jun-ichi IWATA, \\ Kouji KOMURO, and Yoshiyuki TAKADA \\ Department of Chemical Process Engineering, Faculty of Engineering, \\ Hokkaido University, Sapporo 060, Japan.
}

(Received June 8, 1979)

\begin{abstract}
The addition of alkylaluminum chlorides to $o$-allylphenyl methacrylate (APM) has been reported to produce effects different from that of $o$-allylphenyl acrylate (APA). For the cyclopolymerization of $\mathrm{APM}$ in the presence of $\mathrm{AlEt}_{2} \mathrm{Cl}$, a rapid polymerization was induced. The extent of cyclization, however, was extremely small as compared with that of APA. Moreover, it was characteristic of APM that the oligomers were preferentially produced above the $\mathrm{Al} / \mathrm{M}$ molar ratio of 1.0. In the presence of $\mathrm{AlEtCl}_{2}$, the rate of polymerization was smaller than that in the case of $\mathrm{AlEt}_{2} \mathrm{Cl}$, but the extent of cyclization was far larger and increased to $92 \%$ at a $\mathrm{Al} / \mathrm{M}$ molar ratio of 1.25. The value of $k_{\mathrm{p}} / k_{\mathrm{c}}$, the ratio of rate constants for linear propagation and cyclization, for APM capable of forming eight-membered rings, was comparable to those values of the analogous acrylic monomers capable of forming eleven- and thirteen-membered rings. There were indications that the effects of alkylaluminum chlorides on the cyclopolymerization should be smaller for the methacrylic monomers than for the acrylic monomers.
\end{abstract}

KEY WORDS o-Allylphenyl Methacrylate / Cyclopolymerization / Radical Polymerization / Diethylaluminum Chloride / Ethylaluminum Chloride / Cyclization Constant / Oligomer / GPC /

In a previous paper, we reported that nonconjugated dienes containing electropositive and electronegative double bonds, namely, $o$-allylphenyl acrylate (APA) $)^{1}, 2$-(o-allylphenoxy)ethyl acrylate, ${ }^{2}$ and 4-(o-allylphenoxy)butyl acrylate ${ }^{2}$ had their cyclopolymerization tendency greatly increased by alkylaluminum chlorides. Further, it was recognized, using the cyclocopolymerization of these monomers with $p$-chlorostyrene, ${ }^{3}$ and the polymerization of $o$-vinylphenyl acrylate, ${ }^{4}$ that the cyclopolymerization is similar in character to the alternating copolymerization in the presence of alkylaluminum chlorides.

The polar vinyl compounds of the acrylic and methacrylic types form the most important group of electron acceptor monomers for the alternating copolymerization. ${ }^{5}$ A difference between the reactivities of the acrylic and the methacrylic ester disappears by forming a complex with $\mathrm{ZnCl}_{2}$ in the mutual copolymrization. ${ }^{6} \mathrm{On}$ the other hand, there is a subtle difference between these, as can be seen even by the action of a complexing agent in the copolymerization with electron donor monomers. ${ }^{7}$ Therefore, it is interesting to study this difference through the effects of alkylaluminum chloride on the cyclopolymerization of $o$-allylphenyl methacrylate (APM) (I) and APA. The polymerization of APM was reported by Solomon et al., ${ }^{8-10}$ who used the alkylaluminum chlorides as initiators, but not as complexing agents related to the cyclopolymerization. This paper deals with the character of APM for the cyclopolymerization in the presence of $\mathrm{AlEt}_{2} \mathrm{Cl}$ and $\mathrm{AlEtCl}_{2}$ in comparison with that of APA.

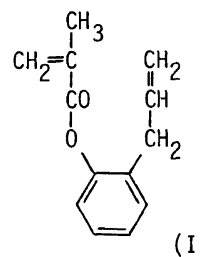


K. Yokota, N. Kaneko, J. Iwata, K. Komuro, and Y. Takada

\section{EXPERIMENTAL}

\section{Reagents}

$o$-Allylphenyl methacrylate was obtained from methacryloyl chloride and $o$-allylphenol. The fraction boiling at $131-132^{\circ} \mathrm{C}(4 \mathrm{mmHg})$ was collected: $n_{\mathrm{D}}^{25} 1.515$ [lit. ${ }^{8}$ bp $101-102^{\circ} \mathrm{C}[1.5 \mathrm{mmHg}] . n_{\mathrm{D}}^{25}$ 1.5205]; $d_{4}^{15} 1.0271$. Diethylaluminum chloride and ethylaluminum dichloride were kindly supplied by Mitsui Petrochemical Industries, Ltd.

\section{Polymerization}

The polymerizations were carried out as described in a previous paper. ${ }^{1}$

\section{Analysis}

The extent of cyclization in polymers and the composition in copolymers were determined by the procedure described in the previous papers. ${ }^{1.2}$ The molecular weights of polymer samples were measured in benzene at $40^{\circ} \mathrm{C}$ by using a vapor pressure osmometer (Hitachi Ltd., Model 117). The product distributions were determined through polystyrene gel columns (Shodex A-802 and A-803), using a liquid chromatograph (Yanagimoto Ltd., Model L1030).

\section{RESULTS AND DISCUSSION}

Radical Polymerization of o-Allylphenyl Methacrylate (APM)

Experimental results are shown in Table I. Figure
Table I. Radical polymerization of $o$-allylphenyl methacrylate $^{a}$

\begin{tabular}{|c|c|c|c|c|}
\hline$[\mathrm{M}]$ & Time & Conversion & $\begin{array}{l}\text { Extent of } \\
\text { cyclization }\end{array}$ & MW \\
\hline $\mathrm{moll}^{-1}$ & h & $\%$ & $\%$ & \\
\hline 5.08 & 1 & 3.4 & 0 & 30900 \\
\hline 2.52 & 2 & 13.3 & 12.5 & 27400 \\
\hline 1.21 & 3.5 & 6.2 & 22.0 & 13200 \\
\hline 0.81 & 12 & 14.4 & 25.0 & 12900 \\
\hline 0.51 & 12 & 11.3 & 30.0 & 10900 \\
\hline
\end{tabular}

${ }^{a}$ Solvent, toluene; AIBN/M molar ratio, 0.012; temp, $60^{\circ} \mathrm{C}$.

1(a) shows the IR spectrum of a polymer. In the spectrum the presence of absorption bands of 910 and $990 \mathrm{~cm}^{-1}$ is indicative of a large amount of unsaturations in the form of pendant allylic double bonds, as shown by the absence of the metacrylic double bonds that would show absorption at $800 \mathrm{~cm}^{-1}$. Since the amount of unsaturations decreases with decreasing monomer concentration, the polymerization is accompanied by a cyclization mechanism and can yield the structural units of methacrylic (II), and of eight-membered cyclic (III) and/or of seven-membered cyclic type (IV).

The extent of cyclization varied from 0 to $30 \%$ with the monomer concentration. The following relation between the fraction of cyclized units $f_{\mathrm{c}}$ and monomer concentration $[\mathrm{M}]$ has been derived by Roovers and Smets ${ }^{11}$

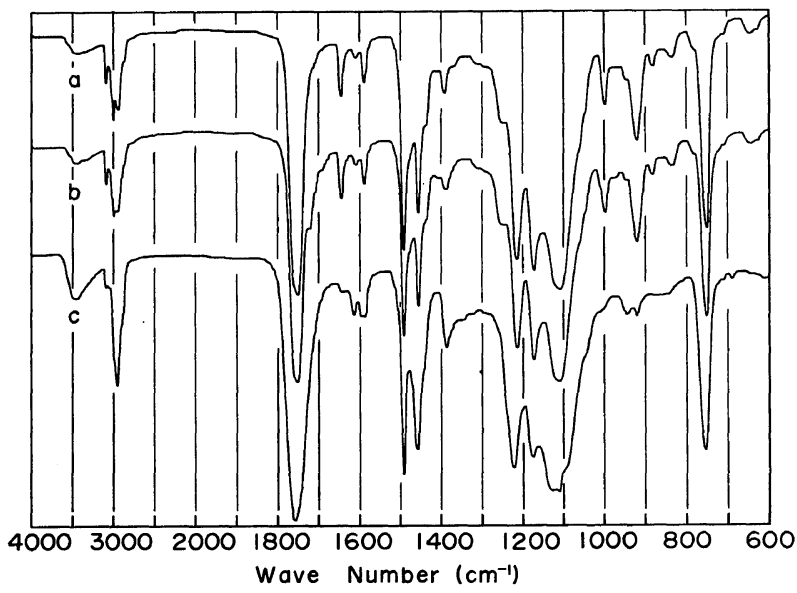

Figure 1. IR spectra of poly (o-allylphenyl methacrylate) prepared: (a) with $\mathrm{AIBN}$ at $60^{\circ} \mathrm{C}, f_{\mathrm{c}}=0.25$; (b) in the presence of $\mathrm{AlEt}_{2} \mathrm{Cl}, f_{\mathrm{c}}=0.275$; (c) in the presence of $\mathrm{AlEtCl}_{2}, f_{\mathrm{c}}=0.88$. 
Cyclopolymerization in the Presence of $\mathrm{AlEt}_{n} \mathrm{Cl}_{3-n}$. V.<smiles>C=Cc1ccccc1O[Ge]C(C)(C)CC</smiles>

(II)

$$
\frac{1}{f_{\mathrm{c}}}=1+\frac{k_{\mathrm{p}}}{k_{\mathrm{c}}}[\mathrm{M}]
$$

where $k_{\mathrm{p}}$ and $k_{\mathrm{c}}$ are the rate constants for linear propagation and cyclization, respectively. Plots of $1 / f_{\mathrm{c}}$ vs. [M] were linear; the slope corresponded to $k_{\mathrm{p}} / k_{\mathrm{c}}=2.33 \mathrm{lmol}^{-1}$ which is much larger than the value of $0.671 \mathrm{~mol}^{-1}$ for APA. The intercept, however, failing to pass through 1.0, had a value of 2.1, and 1.65 for APA. ${ }^{1}$ Thus, APM has a tendency for cyclopolymerization much smaller than APA.

\section{Cyclopolymerization in the Presence of $\mathrm{AlEt}_{2} \mathrm{Cl}$}

The polymerization of APM with $\mathrm{AlEt}_{2} \mathrm{Cl}$ in toluene was accompanied by development of a yellow color which became deeper with increasing $\mathrm{Al} / \mathrm{M}$ molar ratio. The polymers obtained were white<smiles>CC[C]1Oc2ccccc2CC1CC</smiles>

(IV)
(III)<smiles>CC1CC2CC(C)CC(C1)Oc1ccccc1O2</smiles>

amorphous powders or glassy solids and were soluble in ordinary solvents. Figure 1(b) shows that the IR spectrum of a polymer has no substantial difference with that of the polymer obtained by the conventional radical polymerization.

Experimental results are shown in Table II. The polymerization proceeded at a rate which was larger than that in the radical polymerization and that even in the case of $\mathrm{APA}^{1}$ under comparable conditions. The extent of cyclization, however, was much the same value obtained by radical polymerization, except that a slight increase was found at a $\mathrm{Al} / \mathrm{M}$ molar ratio in the range $0.6-0.8$. The molecular weight was very small. The polymerization at reduced temperature $\left(0^{\circ} \mathrm{C}\right)$ produced polymers with a somewhat increased molecular weight, but with an extreme decrease in the extent of cyclization. The

Table II. Polymerization of $o$-allylphenyl methacrylate in the presence of $\mathrm{AlEt}_{2} \mathrm{Cl}^{\mathrm{a}}$

\begin{tabular}{|c|c|c|c|c|c|c|}
\hline \multirow{2}{*}{$\begin{array}{c}\mathrm{Al} / \mathrm{M} \text {, } \\
\text { molar } \\
\text { ratio }\end{array}$} & \multicolumn{3}{|c|}{ Polymerization } & \multicolumn{3}{|c|}{ Polymer } \\
\hline & $\operatorname{Temp} /{ }^{\circ} \mathrm{C}$ & Time $/ \mathrm{h}$ & Conversion $/ \%$ & Yield $^{\mathbf{b}} / \%$ & $\begin{array}{c}\text { Extent of } \\
\text { cylization } / \%\end{array}$ & MW \\
\hline 0.1 & 40 & 1 & 38.1 & 27.1 & 17.5 & 3300 \\
\hline 0.2 & & & 62.5 & 50.7 & 13.0 & 2600 \\
\hline 0.4 & & & 75.7 & 53.9 & 17.0 & 2400 \\
\hline 0.6 & & & 74.6 & 27.6 & 28.0 & 2300 \\
\hline 0.8 & & & 78.2 & 12.0 & 27.5 & 2200 \\
\hline 1.0 & & & 77.8 & 1.5 & - & - \\
\hline 1.5 & & & 58.7 & 0 & - & - \\
\hline 2.0 & & & 54.5 & 0 & - & - \\
\hline 0.1 & 0 & 24 & 15.2 & 10.7 & 7.0 & 7400 \\
\hline 0.2 & & & 37.7 & 30.1 & 7.0 & 6300 \\
\hline 0.4 & & & 52.1 & 48.3 & 7.5 & 6000 \\
\hline 0.6 & & & 61.6 & 47.7 & 9.5 & 4100 \\
\hline 0.8 & & & 57.7 & 33.5 & 7.0 & 3300 \\
\hline 1.0 & & & 46.3 & 16.0 & 4.0 & 3200 \\
\hline 1.5 & & & 25.6 & 0 & - & - \\
\hline 2.0 & & & 21.8 & 0 & - & - \\
\hline
\end{tabular}

a Solvent, toluene; $[\mathrm{M}], 0.50 \mathrm{~mol}^{-1} ; \mathrm{AIBN} / \mathrm{M}$ molar ratio, 0.012 ; temp, $40^{\circ} \mathrm{C}$.

b Yield calculated on the basis of monomer charged. 
decrease in the extent of cyclization corresponds exactly to that brought on by lowering the temperature for radical cyclopolymerization. The rapid polymerization at $40^{\circ} \mathrm{C}$ can be attributed to the effective production of radical by the action of $\mathrm{AlEt}_{2} \mathrm{Cl}^{12}{ }^{12}$ Thus, the addition of $\mathrm{AlEt}_{2} \mathrm{Cl}$ had a slight effect on the propagation process, but a considerable effect on the initiation process. This is very different from the case of APA in which $\mathrm{AlEt}_{2} \mathrm{Cl}$ was effective for the propagation process.

Table IV shows the dependence of the extent of cyclization on monomer concentration. The experimental data, however, could not be fitted by a straight line when plotted according to eq 1 . This deviation might be attributed to the fact that the effects of $\mathrm{AlEt}_{2} \mathrm{Cl}$ on the elementary processes were different in monomer concentration.

The yield of polymer attained a maximum at the $\mathrm{Al} / \mathrm{M}$ molar ratio between 0.2 and 0.4 at $40^{\circ} \mathrm{C}$ as shown in Table II; this is the same situation as in the case of APA. ${ }^{1}$ However, the yield is not consistent

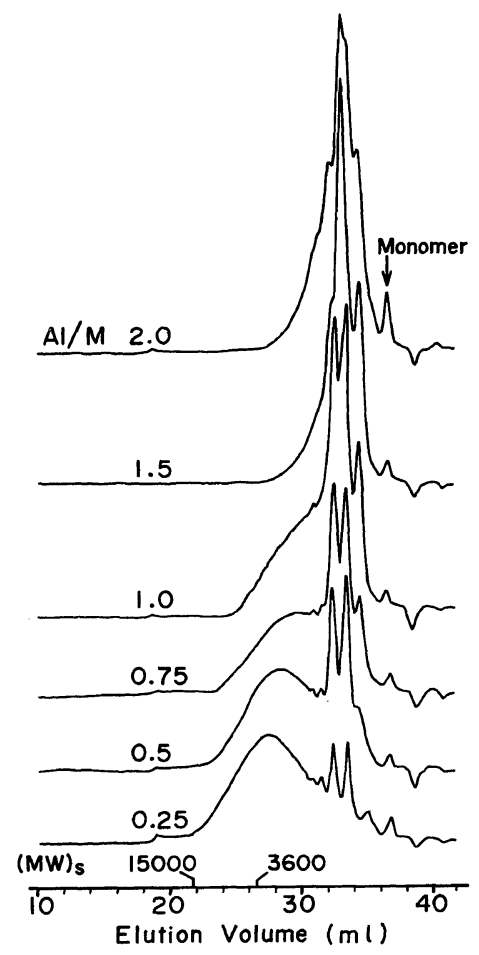

Figure 2. GPC traces of the products from the polymerization of $o$-allylphenyl methacrylate in the presence of $\mathrm{AlEt}_{2} \mathrm{Cl}$ : $(\mathrm{MW})_{\mathrm{s}}$, molecular weight based on polystyrene calibration. with the consumption of monomer, namely, the conversion. The reasons for this discrepancy can be elucidated by examining the GPC analyses of the crude products. As shown in Figure 2, over a fairly wide range of experimental conditions, the GPC traces show two clearly defined distributions, one shifting to lower molecular weight with increasing $\mathrm{Al} / \mathrm{M}$ molar ratio, and the other corresponding to the oligomers at the elution volume in the range 32 $35 \mathrm{ml}$, varing the proportions sensitive to conditions of preparation. Thus, the formation of oligomers can cause this discrepancy. For comparison with the results, the GPC traces of the product obtained by the polymerization of APA under comparable conditions are shown in Figure 3. A considerable amount of the product was insoluble in THF, but considerably soluble in chloroform. Although the production of oligomers is shown also in this case, the proportion is not so great as that in the case of APM. Therefore, the preferential production of oligomers, especially above the $\mathrm{Al} / \mathrm{M}$ molar ratio of 1.0 , is the outstanding characteristics of APM.

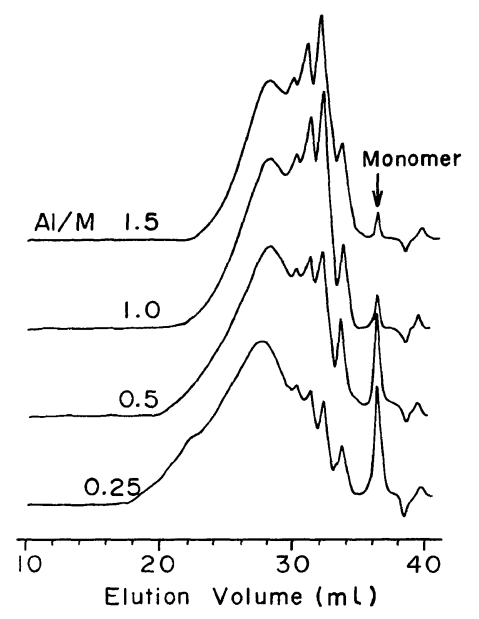

Figure 3. GPC traces of the products from the polymerization of $o$-allylphenyl acrylate in the presence of $\mathrm{AlEt}_{2} \mathrm{Cl}$.

The addition of $\mathrm{AlEt}_{1.5} \mathrm{Cl}_{1.5}$ exhibited no significant difference in polymerization behavior; this is entirely different from that of APA on which $\mathrm{AlEt}_{1.5} \mathrm{Cl}_{1.5}$ had an effect rather similar to that of $\mathrm{AlEtCl}_{2}$.

Cyclopolymerization in the Presence of $\mathrm{AlEtCl}_{2}$ As the polymerization proceeded, the solution 
Cyclopolymerization in the Presence of $\mathrm{AlEt}_{n} \mathrm{Cl}_{3-n}$. V.

Table III. Polymerization of $o$-allylphenyl methacrylate in the presence of $\mathrm{AlEtCl}_{2}{ }^{\mathrm{a}}$

\begin{tabular}{|c|c|c|c|c|c|c|c|}
\hline \multirow{2}{*}{$\begin{array}{c}\mathrm{Al} / \mathrm{M} \text {, } \\
\text { molar } \\
\text { ratio }\end{array}$} & \multirow{2}{*}{ Conversion $/ \%$} & \multicolumn{3}{|c|}{ Polymer $S^{b}$} & \multicolumn{3}{|c|}{ Polymer $\mathrm{P}^{\mathrm{c}}$} \\
\hline & & Yield $/ \%$ & $\begin{array}{c}\text { Extent of } \\
\text { cyclization } / \%\end{array}$ & MW & Yield $/ \%$ & $\begin{array}{c}\text { Extent of } \\
\text { cyclization } / \%\end{array}$ & MW \\
\hline 0.25 & 32.5 & 13.5 & 61.0 & 4200 & 2.0 & 68.5 & - \\
\hline 0.5 & 60.4 & 15.8 & 64.0 & 3200 & 14.2 & 81.0 & 2500 \\
\hline 0.75 & 70.4 & 6.6 & 71.5 & 3400 & 21.1 & 77.0 & 2100 \\
\hline 1.0 & 78.0 & 0 & - & - & 18.6 & 88.0 & 2200 \\
\hline 1.25 & 63.1 & 5.7 & 92.0 & 3000 & 1.9 & - & \\
\hline 1.5 & 56.8 & 1.7 & 89.5 & - & 0 & & \\
\hline 2.0 & 51.8 & 0 & & & 0 & & \\
\hline
\end{tabular}

a Solvent, toluene; [M], $0.50 \mathrm{mol1}^{-1}$; AIBN/M molar ratio, 0.012 ; temp, $40^{\circ} \mathrm{C}$; time, $24 \mathrm{~h}$.

b Polymer $\mathrm{S}$ was obtained from the solution in the reaction mixture.

c Polymer $\mathrm{P}$ was obtained from the precipitate in the reaction mixture.

d Yield calculated on the basis of monomer charged.

gradually changed from yellow to red and became heterogeneous at the $\mathrm{Al} / \mathrm{M}$ ratio between 0.25 and 1.0. After being poured into a large amount of methanol, the reaction mixture gave the polymers from both the solution and the precipitate, and are called polymer $\mathrm{S}$ and $\mathrm{P}$, respectively. Polymer $\mathrm{S}$ was a colorless amorphous solid and polymer $\mathrm{P}$ a yellow solid. Above the $\mathrm{Al} / \mathrm{M}$ molar ratio of 1.0 , the solution was invariably a yellow color and homogeneous. All the polymers obtained, even in heterogeneous reaction system, were soluble in benzene, carbonterachloride, and chloroform.

Experimental results are shown in Table III. The IR spectrum of a polymer shows that the intensities of the absorptions due to the residual allylic double bonds diminished greatly as shown in Figure 1 (c). The rate of polymerization was rather reduced by the action of $\mathrm{AlEtCl}_{2}$; this exhibited a striking contrast to the very rapid polymerization of APA. Polymer P had a somewhat higher extent of cyclization than polymer S, but polymer S had a slightly larger molecular weight. The extent of cyclization was as high as $92 \%$ of the maximum at the $\mathrm{Al} / \mathrm{M}$ molar ratio of $1.25 . \mathrm{AlEtCl}_{2}$ enhanced the electron-accepting property of methacrylic group, accelerating the intramolecular cyclization with the electrondonating group. Thus, the propagation process was profoundly influenced. The effect of $\mathrm{AlEtCl}_{2}$ on the cyclopolymerization tendency is superior beyond comparison with that of $\mathrm{AlEt}_{2} \mathrm{Cl}$.

The cyclized polymer contains unit (III) or (IV). In order to clarify the cyclic structure, the polymer was given the same treatment as it was in the case of APA, ${ }^{1}$ 2-AOEA and 4-AOBA. ${ }^{2}$ The cyclized polymer is transformed into a methylated polymer corresponding to the copolymer of methyl methacrylate and $o$-methoxyallylbenzene, as shown in eq 2 and 3 . Because the mode of addition predominates the head-to-tail bonding in conventional and alternating ${ }^{13}$ copolymerization, the copolymer is com-

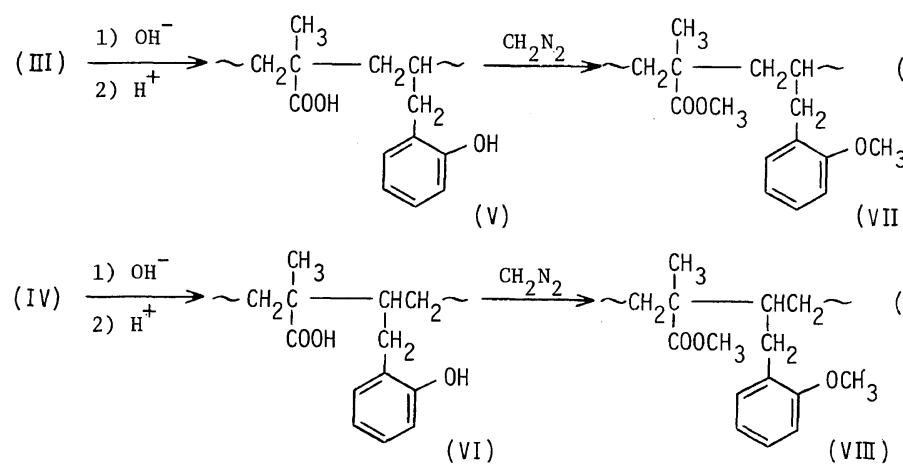


posed of the bonding indicated in (VII). The head-totail polymers generally have IR absorption characteristics different from those of the head-to-head isomers. ${ }^{14-16}$ The copolymerizations of methyl methacrylate $\left(\mathrm{M}_{1}\right)$ and $\theta$-methoxyallylbenzene $\left(\mathrm{M}_{2}\right)$ were carried out in the presence of $\mathrm{AlEtCl}_{2}$. The results are shown in Figure 4. The copolymerization parameters characterizing the composition curve could not be estimated using the usual Mayo-Lewis equation. The copolymerization lacks the alternating tendency, in contrast with the system of methyl acrylate-o-methoxyallylbenzene, ${ }^{1}$ indicating also the difference between the reactivities of the acrylic and the methacrylic ester in the acceptor monomers. The IR spectrum of the methylated polymer derived from the cyclized polymer with $f_{\mathrm{c}}=0.75$ was com-

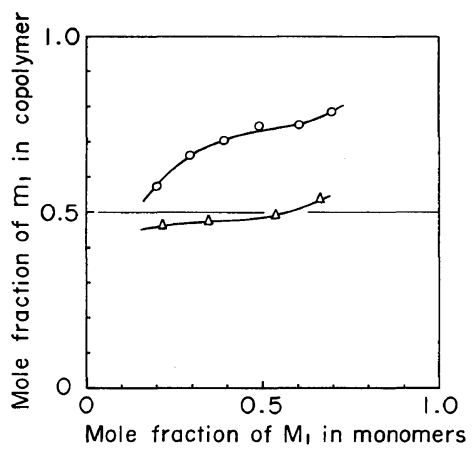

Figure 4. Variation of copolymer composition with monomer feeds $(O)$ in the system of methyl methacrylate $\left(\mathrm{M}_{1}\right)-O$-methoxyallylbenzene $\left(\mathrm{M}_{2}\right)$ and $(\triangle)$ in the system of methyl acrylate $\left(\mathrm{M}_{1}\right)-o$-methoxyallylbenzene $\left(\mathrm{M}_{2}\right)^{1}$ in the presence of $\mathrm{AlEtCl}_{2}: \mathrm{M}_{1}, 3.6 \mathrm{mmol}$; $\mathrm{AIBN}, 0.3 \mathrm{mmol}$; $\mathrm{Al} / \mathrm{M}$ molar ratio, 1.0 ; solvent, toluene, $1.5 \mathrm{ml}$; temp, $40^{\circ} \mathrm{C}$.

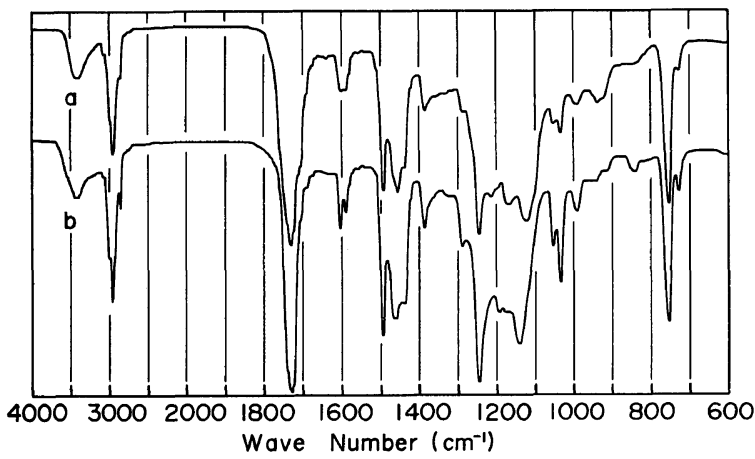

Figure 5. IR spectra of (a) the polymer derived from poly $(o$-allylphenyl methacrylate $), f_{\mathrm{c}}=0.75$, by hydrolysis and treatment with diazomethane, and (b) the copolymer, $m_{1}=0.58$, prepared from the system of methyl methacrylate- $O$-methoxyallylbenzene in the presence of $\mathrm{AlEtCl}_{2}$.

Table IV. Effect of monomer concentration on the polymerization of $o$-allylphneyl methacrylate in the presence of alkylaluminum chlorides ${ }^{\mathrm{a}}$

\begin{tabular}{ccccc}
\hline$[\mathrm{M}] / \mathrm{mol1}^{-1}$ & $\begin{array}{c}\text { A1/M, } \\
\text { molar ratio }\end{array}$ & Time/min & Conversion/\% & $\begin{array}{c}\text { Extent of } \\
\text { cyclization/\% }\end{array}$ \\
\hline $\mathrm{AlEt}_{2} \mathrm{Cl}$ & & & & \\
2.24 & 0.2 & 2 & 41.0 & 0 \\
1.70 & 0.2 & 7 & 36.7 & 2.0 \\
1.18 & 0.2 & 20 & 29.7 & 9.5 \\
0.65 & 0.2 & 40 & 13.1 & 12.0 \\
0.34 & 0.2 & & & \\
\hline $\mathrm{AlEtCl}{ }_{2}$ & & 30 & 5.9 & 70.5 \\
2.01 & 1.0 & 30 & 5.5 & 76.5 \\
1.52 & 1.0 & 60 & 8.3 & 88.0 \\
1.01 & 1.0 & 300 & 4.5 & 88.0 \\
\hline 0.51 & 1.0 & & \\
\hline
\end{tabular}

${ }^{\text {a }}$ Solvent, toluene; AIBN/M molar ratio, 0.01 ; temp, $40^{\circ} \mathrm{C}$. 
pared with that of the copolymer with the mole fraction $m_{1}=0.58$. The composition of the methylated polymer corresponded to $m_{1}=0.57$ which was estimated from $f_{\mathrm{c}}=0.75$ in the cyclized polymer. As shown in Figure 5, the methylated polymer has IR absorption characteristics very similar to those of the copolymer. The difference in the intensities of some absorption bands is caused by participation of the end units since the methylated polymer was derived from the cyclized polymer with considerably low molecular weight. The similarity of these spectra indicates that APM polymerized to give polymers containing eight-membered rings (III), as in the case of APA.

The dependence of the extent of cyclization on the monomer concentration is shown in Table IV. When plotted $1 / f_{\mathrm{c}} v s .[\mathrm{M}]$, the experimental data satisfied eq 1 with an intercept at a infinite dilution to complete the cyclization: the ratio of $k_{\mathrm{p}} / k_{\mathrm{c}}=0.21$ $1 \mathrm{~mol}^{-1}$. The value of $k_{\mathrm{p}} / k_{\mathrm{c}}$ obtained is much larger than that of $0.0451 \mathrm{~mol}^{-1}$ for APA, but is comparable to those of $0.17 \mathrm{~mol}^{-1}$ for $2-\mathrm{AOEA}^{2}$ and 0.27 $1 \mathrm{~mol}^{-1}$ for 4-AOBA. ${ }^{2}$

The cyclopolymerization tendency of APM is comparable to that of 2-AOEA and 4-AOBA, acrylic esters, capable of forming the eleven- and the thirteen-membered ring, respectively. The effect of $\mathrm{AlEtCl}{ }_{2}$ on the methacrylic ester is much smaller compared with that on the acrylic ester.

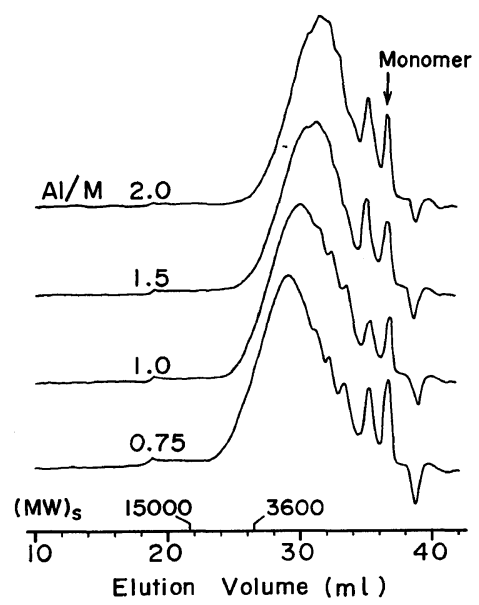

Figure 6. GPC traces of the products from the polymerization of $o$-allylphenyl methacrylate in the presence of $\mathrm{AlEtCl}_{2}:(\mathrm{MW})_{\mathrm{s}}$, molecular weight based on polystyrene calibration.
The yield of polymer was not consistent with the consumption of monomer in this case as well. The content of soluble product increased with increasing $\mathrm{Al} / \mathrm{M}$ molar ratio. The GPC traces of crude products are shown in Figure 6. The higher molecular weight peak was found with the upward shift of the elution volume as the $\mathrm{Al} / \mathrm{M}$ molar ratio increased. In contrast with the situation for $\mathrm{AlEt}_{2} \mathrm{El}$, the oligomer was produced in only low yield and its population was independent of the $\mathrm{Al} / \mathrm{M}$ molar ratio used. Therefore, the formation of soluble products is simply ascribed to the lowering of the molecular weight of polymer by the action of $\mathrm{AlEtCl}_{2}$. Also, the preferential production of oligomers is characteristic of the polymerization of APM in the presence of $\mathrm{AlEt}_{2} \mathrm{Cl}$.

\section{REFERENCES}

1. K. Yokota, N. Hirayama, and Y. Takada, Polym. J., 7, 629 (1975).

2. K. Yokota, T. Kakuchi, and Y. Takada, Polym. J., 8, 495 (1976).

3. K. Yokota, T. Kakuchi, and Y. Takada, Polym. J., 10, 19 (1978).

4. T. Kakuchi, K. Yokota, and Y. Takada, Polym. J., 11, 7 (1979)

5. M. Hirooka, H. Yabuuchi, S. Kawasumi, and K. Nakaguchi, J. Polym. Sci., Polym. Chem. Ed., 11, 1281 (1973)

6. V. P. Zubov, L. I. Valuev, V. A. Kavanov, and V. A. Kargin, J. Polym. Sci., A-1, 9, 833 (1971).

7. J. M. KcKenna and A. L. Logothetis, Appl. Polym. Symp., No. 26, 99 (1975).

8. O. F. Solomon, M. Corciovei, and V. Tărărescu, $J$. Appl. Polym. Sci., 11, 1631 (1967).

9. O. F. Solomon, M. Corciovei, and E. Beral, J. Polym. Sci., B, 6, 507 (1968).

10. O. F. Solomon, M. Corciovei, I. Gabe, and E. Beral, J. Polym. Sci., A-1, 9, 509 (1971).

11. J. Roovers and G. Smets, Makromol. Chem., 60, 89 (1963).

12. N. G. Gaylord and S. Maiti, Makromol. Chem., 142, 101 (1971).

13. F. Shepherd and H. J. Harwood, J. Polym. Sci., B, 9, 419 (1971).

14. T. Otsu, S. Aoki, and R. Nakatani, Makromol. Chem., 134, 331 (1970).

15. T. Tanaka and O. Vogl, Polym. J., 6, 522 (1974).

16. T. Ots, Quach Loc, T. Ohya, and S. Mori, Polym. Prepr., Jpn., 27, 716 (1978). 